\title{
Study of fouling in graphite blocks (cross flow) heat exchanger of phosphoric acid concentration process
}

\author{
Rania Jradi ${ }^{1, *}$, Christophe Marvillet ${ }^{2}$, Mohamed Razak Jeday ${ }^{1}$ \\ ${ }^{1}$ Research Laboratory “Process, Energy, Environment \& Electrical Systems”, National Engineering School of Gabes, Tunisia \\ ${ }^{2}$ CMGPCE Laboratory, French Institute of Refrigeration (IFFI), National Conservatory of Arts and Crafts(CNAM), Paris, France
}

\begin{abstract}
Fouling in phosphoric acid concentration process of preheat exchangers is a chronic operational problem that compromises energy recovery in these systems. Progress is hindered by the lack of quantitative knowledge of the dynamic effects of fouling on heat exchanger transfer. The subject of this work is an experimental determination of the thermal fouling resistance in the graphite blocks heat exchanger installed in a phosphoric acid concentration process. By measuring the inlet and outlet temperatures and mass flows of fluids, the overall heat transfer coefficient has been determined. Determining the overall heat transfer coefficient for the heat exchanger with clean and fouled surfaces, the fouling resistance was calculated. The results obtained from the heat exchanger studied, show that the fouling resistance increase with time presenting an exponential evolution in agreement with the model suggested by Kern and Seaton, with the existence of fluctuation caused by the instability of the flow rate and the temperature. Bad cleaning of the heat exchanger involves the absence of the induction period and consequently, causes high values of the fouling resistance and of the deposit fouling during a relatively short period of time.
\end{abstract}

\section{Introduction}

The most serious and complex problem faced by various industries is the accumulation, on the heat transfer surfaces, of organic compounds or various particles dissolved or present as a suspension in the fluid [1]. This phenomenon which called fouling affects the device functioning by reducing their thermal efficiency and by creating a considerable pressure loss. This causes a significant economic loss due to the pumping and the frequent cleaning of facilities [2]. Fouling in heat transfer systems is often inevitable and reduces energy efficiency and the functionality of the facility. Mitigation of fouling, and effective cleaning strategies, require both understanding of the mechanisms involved in deposition and cleaning [3].

Numerous heat transfer systems subjected to fouling, reduces the efficiency of heat transfer and limits productivity [4]. Phosphoric acid fouling in heat exchangers in the concentration process is a persistent operational problem that compromises energy recovery in these systems. Progress is impeded by the lack of quantitative knowledge of the dynamic effects of fouling on heat transfer exchanger [5]. Typically the phosphoric acid flows through the tube side while the steam flows through the shell side of the heat exchangers [6].

There are a wide variety of deposit problems and facility types susceptible to fouling. A description of the deposit phenomenon for its modelling was presented in [7]. Tools to understand fouling should be developed to provide quantified information for the validation of the fouling models. Several studies have been devoted to the parameters influencing the fouling deposit by scaling. For instance, number of studies have shown that the fouling rate rise by the reduction of the fluid temperature [8].

They are explained by the fact that the velocity and temperature are constant; the increase of the thermal transfer involves the rise of fouling rates. Others have gone to the increase of fouling rates with the fluid temperature [9]. Radhakrishman et al. [6] developed a predictive model using statistical methods and that allows the prediction of the fouling rate and the efficiency decrease of the heat exchanger. Mohanty and Singru [4] used the C-factor for fouling monitoring in shell and tube heat exchanger. Ishiyama et al. [10] address in their work the problem of the inlet temperature monitoring in the event of a disaster using hot flow, within a PHT fouling mitigation strategy based on heat exchanger cleaning. Wang et al. [11], in their results of heat transfer experiments, show that the shell-side heat transfer coefficient of the improved heat exchanger raised by $18.2-25.5 \%$, the overall heat transfer coefficient increased by $15.6-19.7 \%$, and the energy efficiency increased by $12.9-14.1 \%$. Sanaye and Hajabdollahi [12] used a first thermal model which is the $\varepsilon$-NTU method that is applicable to optimal conception of tubular heat exchanger. Most

\footnotetext{
* Corresponding author: raniajradi@yahoo.fr
} 
engineering calculations in heat transfer use the experimental heat transfer coefficients [13]. Heat exchanger fouling used in concentration process is a barrier to their development.

In this study, we will examine the fouling phenomenon of the heat exchanger tubes for the preheated circuit of phosphoric acid in the concentration process. The heat exchanger which is used for the heating of the phosphoric acid is exposed to the fouling problem at the tube side of the heat exchanger. Within this framework, an experimental determination of the thermal fouling resistance, by measuring the inlet and outlet temperatures and mass flows of fluids, allowed to determine the overall heat transfer coefficient. Determining the overall heat transfer coefficient for the heat exchanger with clean and fouled surfaces, the fouling resistance was calculated for the heat exchanger studied.

\section{Industrial process description}

The concentration system used is constituted by a tubular heat exchanger made of graphite blocks (A), a circulating pump (B), a boiler (C), a barometric condenser (D) and a basket filter (E) (Fig.1). The mixture of phosphoric acid (the dilute (1) and the circulating phosphoric acid (2)) leaves the basket filter (3); the centrifugal pump drives it back towards the heat exchanger (4), which is the tube-and shell type [14].

The phosphoric acid crosses the heat exchanger where it is heated from $70{ }^{\circ} \mathrm{C}$ to about $80{ }^{\circ} \mathrm{C}$ using the steam flow (5) which undergoes a condensation at the heat exchanger at a temperature of $120^{\circ} \mathrm{C}$. The condensate outlet $(\boldsymbol{6})$ is sent to a storage tank (F) before being sent back to the utility station. The superheated mixture of phosphoric acid passes then by the boiler (7) where a quantity of water evaporates and the concentrated acid is produced by overflowing in a piping system inside the boiler $(\boldsymbol{8})$. The remaining quantity of phosphoric acid is recycled. The condenser also ensures the incurring of uncondensable gases outgoing of the boiler (9) by the effect of waterfall (10) (Fig.1).

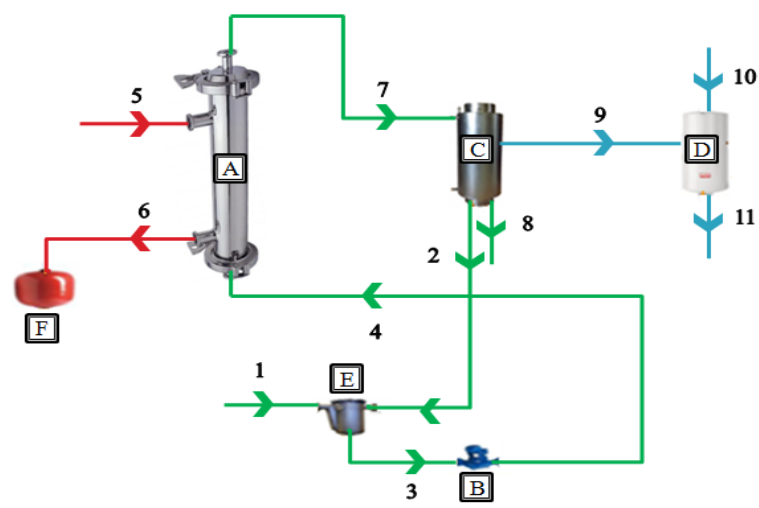

Fig.1. Schematic drawing of the phosphoric acid concentration process.
Our experimental study is based on the following assumptions:

1. Counter current configuration adopted for the flow of two fluids (phosphoric acid and steam).

2. The heat losses were neglected: the phosphoric acid/steam separation surface is the only exchange surface.

3. The condensation of heating steam is total at inlet temperature.

4.Fouling occurs only on the side of the phosphoric acid.

\section{Calculation process of fouling resistance}

The study was done on the level of heat exchanger of the phosphoric acid concentration process. The experimental data was collected out during one year. The method that we used to monitor the fouling evolution consists on carrying out a heat balance at the boundaries of the heat exchanger through the measurements of inlet and outlet temperatures, suction and discharge pressure and acid density. The latter were taken every $2 \mathrm{~h}$ throughout all the day.

This method, although indirect, allow to detect the necessary moment to shut down the installation for cleaning. In the present study, the temporal evolution of the fouling resistance of the phosphoric acid was studied.

The calculation of the fouling resistance (Rf) was carried out using the following relation:

$$
R f(t)=\frac{1}{U_{s}}-\frac{1}{U_{p}}=\frac{1}{U(t)}-\frac{1}{U(t=0)}
$$

The overall heat transfer coefficient at the dirty state $\left(U_{s}=U(t)\right)$ was given in the time course, via the expression:

$$
U_{s}=\left(\frac{\dot{m}_{a c, \text { cir }} \times C p_{a c} \times\left(T_{a c, o u t}-T_{a c, \text { in }}\right)}{A \times F \times \Delta T_{m l}}\right)_{(t)}
$$

This relation is drawn from the evaluation of energy on the heat exchanger assuming the isolated system and the physical properties of the two fluids remaining constant along the exchanger.

In the phosphoric acid concentration process, the operating conditions at the boundary of the heat exchanger are unstable, it is necessary to disclosure the heat exchanger coefficients in proper conditions $\left(\mathrm{U}_{\mathrm{p}}=\right.$ $\mathrm{U}(\mathrm{t}=0))$ corresponding to the new operating conditions. Assuming that the cleaning between operational runs is perfect and the heat exchanger is totally free of fouling at the outset of a new cycle. The initial value of the overall heat transfer coefficient at the beginning of 
every cycle is considered as the value of the overall heat transfer coefficient in the clean state.

$$
U_{p}=\left(\frac{\dot{m}_{a c, c i r} \times C p_{a c} \times\left(T_{a c, o u t}-T_{a c, i n}\right)}{A \times F \times \Delta T_{m l}}\right)_{(t=0)}
$$

To calculate the overall heat transfer coefficients in the clean and fouled state, the mass flow rate of phosphoric acid should be determined by using the following equation:

$$
\dot{m}_{a c, c i r}=\dot{v}_{a c, c i r} \times \rho_{a c}
$$

The volume flow rate of circulating acid is a function of the total manometric head of the pump (HMT) characteristic of the pump used.

$$
\dot{v}_{a c, c i r}=f(H M T)
$$

The measurements collected permit to calculate the total manometric head of the pump (HMT) using the following relation:

$$
H M T=\frac{P_{d i s}-P_{s u c}}{\rho_{a c} \times g}
$$

\section{Results and discussion}

\subsection{Temporal evolution of the fouling resistance}

The evolution of the fouling resistance in the phosphoric acid concentration process of the heat exchanger was followed by a study period quoted previously. The results of the fouling resistance are presented in the curve form on Fig. 2 .

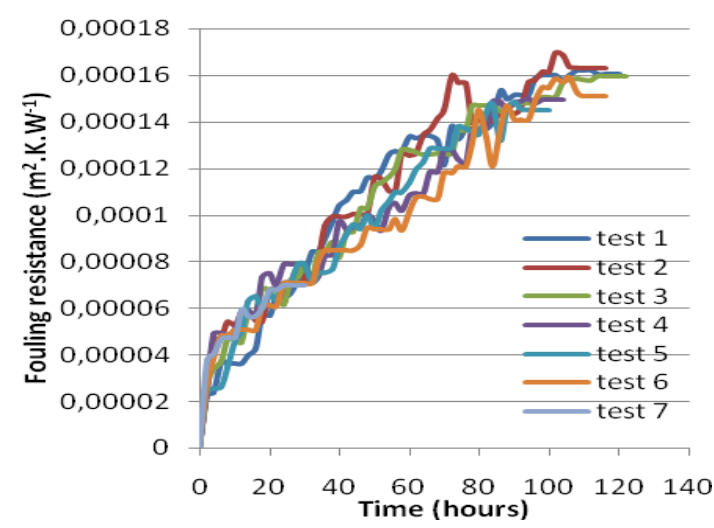

Fig.2. Variation of the fouling resistance as a function of time.

From the values of these resistances, which are higher than zero, the heat exchanger contains, in his surface, the fouling. The curves presented show that the temporal evolution of the fouling resistance, appears to follow an asymptotic evolution, which conforms to the model of Kern and Seaton [18], with the lack of the induction period. This is explained by the fact that there are a time offset between the last cleaning, which corresponds to $\mathrm{t}=0$, and the beginning of this experiments. As it appears clearly, the fouling resistance increases with time until reaching a maximum value, ranging from $6.99 * 10^{-5}$ to $1.65 * 10^{-4}$ $\mathrm{m}^{2} . \mathrm{K} . \mathrm{W}^{-1}$. It can be seen from Fig. 3, the time required to reach a fouling deposit is $90 \mathrm{~h}$ for this type of heat exchanger. As of that moment, the asymptotic zone begins and the fouling thickness does not vary any more overtime.

At that time, it is necessary to stop the heat exchanger for an emergency cleaning.

The fluctuations observed on these curves are caused by the variation of flow rate acting on the shear stress on the wall, causes removal of deposit particles or their deposition depending on the flow rate sent.

So, it is necessary to know the operational parameters which promote the formation of fouling in the concentration process, such as:

- The decrease of the phosphoric acid flow rates, involves the decrease of the fluid speed (phosphoric acid);

- The good quality of the phosphoric acid: a very low content of impurity;

- The washing water of the heat exchanger is treated well and does not pose scaling and corrosion problems.

\subsection{Temporal evolution of the overall heat transfer coefficient}

Fig. 3 shows the temporal evolution of the overall heat transfer coefficient $U(t)$ for the studied heat exchanger. As it can be seen from this figure and Fig.2, the fouling resistance increases over time, which leads to a decrease in the flow of heat exchanged between the phosphoric acid and the steam, and consequently the decrease in the overall heat transfer coefficient. It reaches a minimum value in the end of every cycle, ranging from 1881 to 1983 $\mathrm{W} \cdot \mathrm{m}^{-2} \cdot \mathrm{K}^{-1}$.

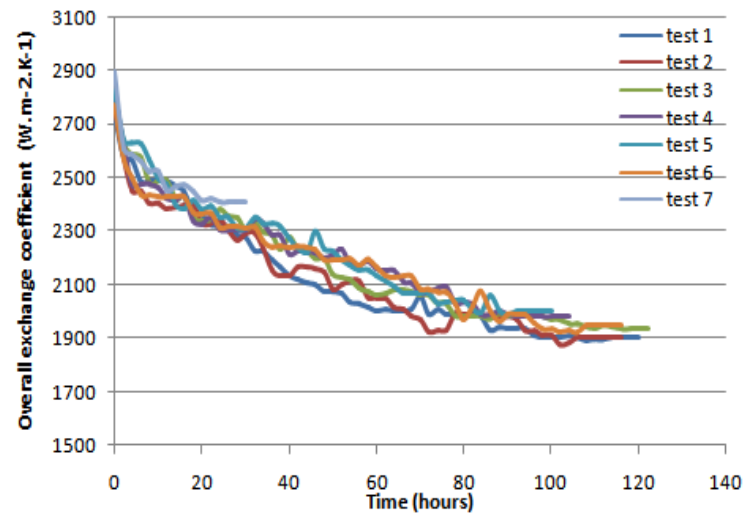

Fig.3. Variation of the overall heat transfer coefficient as a function of time.

\subsection{Temporal evolution of volume flow rates of phosphoric acid}

Fig. 4 shows a temporal evolution of the volume flow rates at the tube side (phosphoric acid) of the heat exchanger. The values for the flow rates are picked up directly from 
the concentration process from the characteristic curve of the pump. Therefore, we note according to this Figure, that the values of volume flow rates of phosphoric acid are very higher and decrease over time. As shown previously according to Fig.2, which represents the increase of the fouling resistance as a function of time in the heat exchanger, we have noticed that this increase caused the decrease of the volume flow rates of fluid (tube side), as of Fig.4.

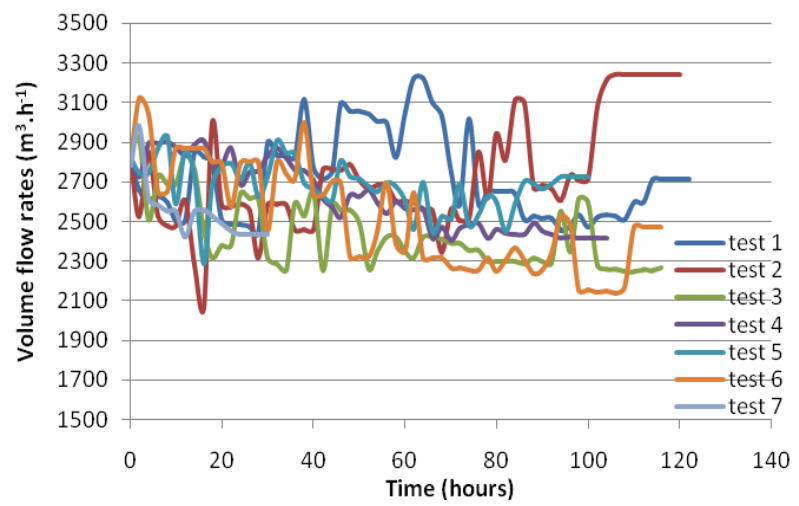

Fig.4.Variation of volume flow rates of phosphoric acid as a function of time.

\subsection{Temporal evolution of difference temperature of phosphoric acid}

The curve giving the variation of the difference temperature of the phosphoric acid according to time is illustrated on Fig. 5. Figs. 2 and 5 show that when the fouling resistance grows, the difference of temperatures decreases.

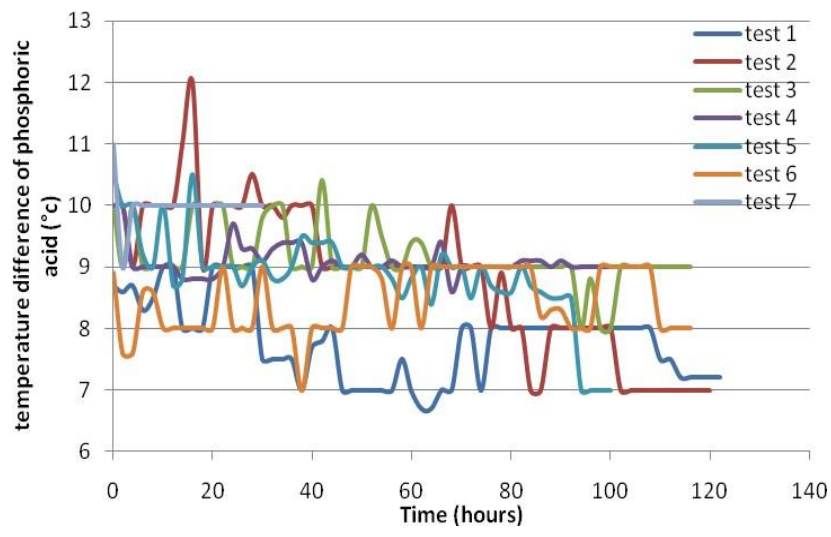

Fig.5.Variation of temperature difference of phosphoric acid as a function of time.

\subsection{Temporal evolution of steam temperature}

Fig.6 shows a temporal evolution of the steam temperature. We note, therefore, according to this Figure, that the steam temperature increases in the time. As shown previously according to Fig.2, which represents the increase of the fouling resistance as a function of time in the heat exchanger, we have noticed that this increase causes the increase of the steam temperature as shown in Fig.6.

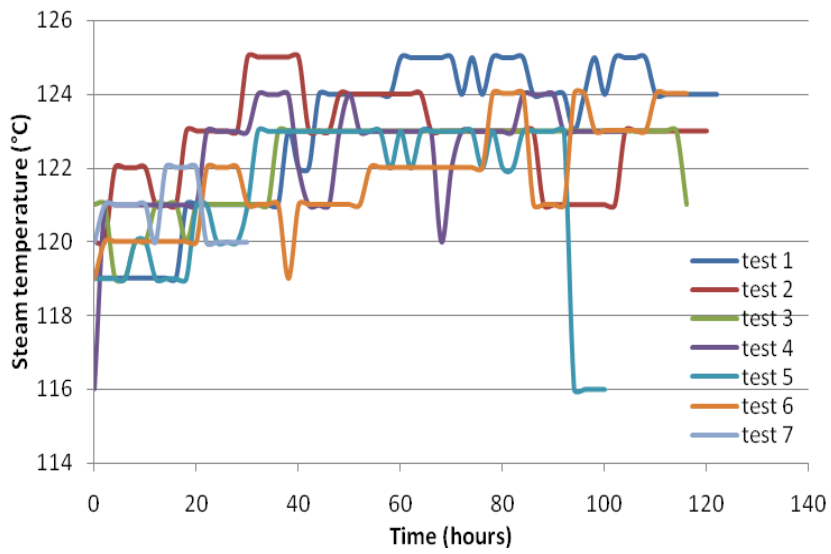

Fig.6. Variation of steam temperature as a function of time.

\subsection{Temporal evolution of phosphoric acid density}

The results obtained of phosphoric acid density are grouped in the Fig.7, where we notice that the density vary with the time.

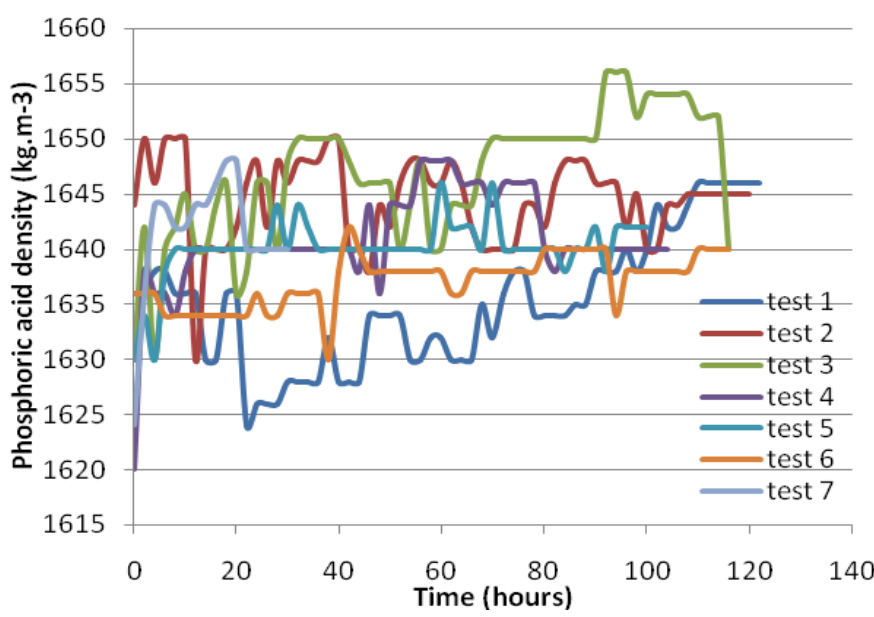

Fig.7. Variation of phosphoric acid density as a function of time.

\subsection{Comparison between experimental data and Kern and Seaton model}

Among the first correlative models allowing the characterization of the kinetics of fouling, we distinguish Kern and Seaton model [1], which its general expression is as following:

$$
R f(t)=R f^{*} *\left(1-e^{-t / \tau}\right)
$$

This model gives satisfactory results. It provides an asymptotic value of the thermal resistance $\mathrm{Rf}^{*}$ as well as the time constant $\tau$, which strongly conditions the accuracy of the model. Table 1 presents the 
identification results of the two parameters $\mathrm{Rf}^{*}$ and $\tau$ for the studied heat exchanger. Fig.8 illustrates the consistency in variation of the fouling resistance over time obtained from both measurement and Kern and Seaton model. This figure shows a good agreement between the Kern and Seaton model and the experimental data with determination coefficient $\mathrm{R}^{2}$ close to 1 (Table 1 ).

Table 1. Values of the asymptotic fouling resistance, the time constant and the determination coefficient for the studied heat exchanger.

\begin{tabular}{c|c}
\hline $\mathbf{R} \mathbf{f}^{\prime \prime}\left(\mathbf{m}^{\mathbf{2}} \cdot \mathbf{K} \cdot \mathbf{W}^{-\mathbf{1}}\right)$ & $1.51 \times 10^{-4}$ \\
\hline $\boldsymbol{\tau}(\mathbf{h})$ & 42.01 \\
\hline $\mathbf{R}^{\mathbf{2}}$ & 0.974 \\
\hline
\end{tabular}

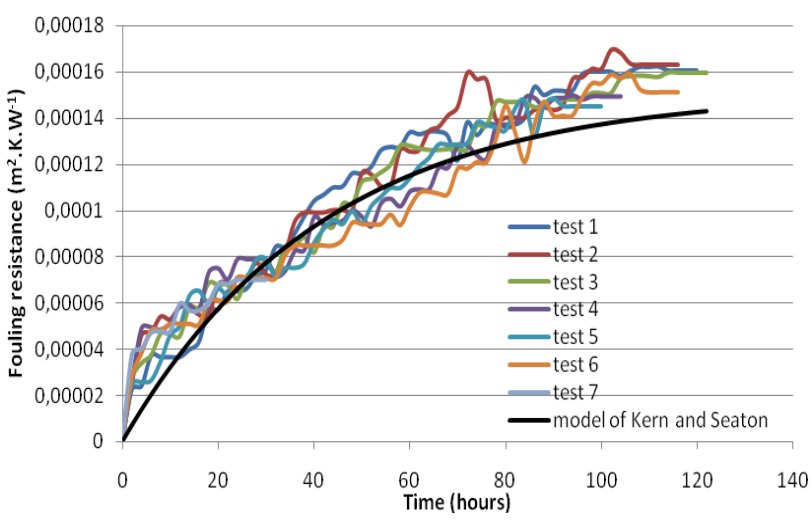

Fig.8. The consistency in variation of the fouling resistance over time.

\section{Conclusion}

The monitoring of heat exchanger allows to fully knowing the fouling evolution under specific conditions of the process. The deposit formation is a thermal resistance that causes significant economic and ecological penalties [15].

The objective of this work was the study of the heat exchanger fouling phenomenon in the concentration process. A large number of plant operating data of the graphite blocks heat exchanger of the phosphoric acid concentration unit were collected every 2 hours for 7 runs, each run is about 3-5 days. These operating parameters allow evaluating the temporal evolution of the fouling resistance, the volume flow rates, the temperature difference of phosphoric acid, the steam temperature and the effect of the phosphoric acid density.

Results indicate that the fouling resistance follows an exponential evolution in conformity with the model of Kern and Seaton with the absence of the induction period, which is explained by a poor cleaning, or a deviation between the present study and the beginning of the functioning of the heat exchanger after the last stop.
In the concentration process, the phosphoric acid flow rates are not maintained constant, they decrease as a function of time, and this is explained by the important production demand as well as the problems which appear when the unit functions.

Concerning the influence of parameters on the fouling resistance, we found an analogy between our experimental results and the theoretical prediction. Indeed, the increase of the fouling resistance causes the decrease of volume flow rates of the phosphoric acid, the decrease of temperature difference of phosphoric acid and the increase of steam temperature and phosphoric acid density. The instability of the operating conditions (flow rates, input and output fluids temperatures, density...) is a favourable factor for the deposits formation in the heat exchanger.

Thus, the experimental data of fouling resistances are compared with Kern and Seaton predictive model. The prediction of the model is in good agreement with the experimental data.

\section{References}

1. Jradi R, Fguiri A, Marvillet C, Jeday M.R. (2019). DOI: 10.5772/intechopen.88936.

2. Farajollahi B, Etemad S. Gh, Hojjat M. Int. J. Heat and Mass Transfer 53, 12 (2010).

3. Pogiatzis T, Ishiyama E.M, Paterson W.R, Vassiliadis V.S, Wilson D.I.. Appl. Energy, 89, 60 (2009).

4. Mohanty D.K, Singru P.M. Int. J. Energy 36, 2899 (2011).

5. Yeap B.L, Wilson D.I, Polley G.T, Pugh S.J. Int. J. Chem. Eng. Research and Design 82, 53 (2004).

6. Radhakrishnan V.R, Ramasamy M, Zabiri H, Thanh V.Do, Tahir N.M, Mukhtar H, Hamdi M.R, Ramli N. Appl. Ther. Eng. 27, 2791 (2007).

7. Vessakosol P, Charoensuk J. Appl. Ther. Eng. 30, 1170 (2010).

8. Srinivasan M, Watkinson A.P. Heat Transfer Eng. 26, 07, (2005).

9. Saleh Z.S, Sheikholeslami R, Watkinson A.P. Heat Transfer Eng 26, 15 (2005).

10. Ishiyama E.M, Heins A.V, Paterson W.R, Spinelli L, Wilson D.I. Applied Thermal Eng. 30, 1852 (2010).

11. Wang S, Wen J, Yanzhong Li.. Applied Thermal Eng. 29; 2433 (2009).

12. Sanaye S, Hajabdollahi H. Applied Thermal Eng. 30, 1937 (2010).

13. Taler D. Heat and Mass Transfer 49, 1125 (2013).

14. Jradi R, Fguiri A, Marvillet C, Jeday M.R. J Stat Mech: Theory Exp, (2019)

15. Salehi H, Zeinali Heris S, Esfandyari M, Koolivand M. Heat and Mass Transfer, 51, 575 (2015). 


\section{Nomenclature}

$\mathrm{Cp} \quad$ Specific heat capacity, $\mathrm{J} \cdot \mathrm{Kg}^{-1} \cdot \mathrm{K}^{-1}$

F Correction Factor $(=1$ for a steam

g $\quad$ Gravity acceleration $\left(=9.81 \mathrm{~m} \cdot \mathrm{s}^{-2}\right)$

HMT Total manometric head of the pump, $m$

$\dot{\mathrm{m}} \quad$ Mass flow rate, $\mathrm{kg} \cdot \mathrm{s}^{-1}$

P Pressure, bar

Q Thermal power, W

Rf Fouling resistance, $\mathrm{m}^{2} . \mathrm{K} . \mathrm{W}^{-1}$

A Area, $\mathrm{m}^{2}$

T Temperature, $\mathrm{K}$

$\mathrm{t} \quad$ Time, $\mathrm{h}$

$\mathrm{U} \quad$ Overall heat transfer coefficient, $\mathrm{W} \cdot \mathrm{m}^{-2} \cdot \mathrm{K}^{-1}$

$\dot{v} \quad$ Volume flow rate, $\mathrm{m}^{3} \cdot \mathrm{h}^{-1}$

\section{Greek letters}

$\tau \quad$ Time required to reach $63.2 \%$ of $\mathrm{Rf}^{*}, \mathrm{~h}$

$\rho \quad$ Density, Kg. $\mathrm{m}^{-3}$

\section{Subscripts}

$\begin{array}{ll}\text { ac } & \text { Acid } \\ \text { cir } & \text { Circulation } \\ \text { dis } & \text { Discharge } \\ \text { in } & \text { Input } \\ \mathrm{ml} & \text { Logarithmic mean } \\ 0 & \text { Clean } \\ \text { out } & \text { Output } \\ \text { st } & \text { Steam } \\ \text { suc } & \text { Suction }\end{array}$

* Asymptotic value 